but these have been under review at Wrightington and the findings agree with those presented in the articles mentioned. I felt that the number of cases, 49, under Dr. Harris et al. was insufficient for drawing much in the way of statistical conclusions, especially for comparison with the other series. I noticed that there was no mention of mortality in the first paper and only $1 \%$ mortality in the second series of 352 osteoarthritic hips. In the older age group, which I studied, the overall mortality was $2.6 \%$ and it was interesting that the mortality was $5.2 \%$ in the males and only $1.8 \%$ in the females, which confirms the clinical impression of many people that elderly men do not withstand surgery as well as women.

The cases included operations performed by registrars, senior registrars, and consultants, so we may conclude that at least some of the reduction in sepsis was due to clean air and the body exhaust system in use at Wrightington. Also, all the cases reviewed had their operations at least 18 months prior to review.

In spite of careful selection the mortality in elderly males is high, so great care must be taken in ensuring that the indications for surgery are sufficient.-I am, etc.,

Broadgreen Hospital,

M. E. Cavendish Broadgreen
Liverpool

1 Cavendish, M. E., Internal Publications, Wrightington Hospital, East Liverpool Regional Hospital Board, 1972. - Charnley, J., fournal of Bone and foint Surgery,
1972, 54B, 61.

\section{Radiation Menopause}

SIR,-While agreeing fully with the conclusions reached in your leading article (13 May, p. 365) on the place of irradiation menopause in the management of dysfunctional uterine bleeding, I feel that not enough distinction has been made in the literature on the relative efficacy of a menopause induced by deep $x$-ray therapy as opposed to the use of radium, since the side effects of the latter procedure are considerably greater.

Radiation menopause was used freely in the Plymouth clinical area after 1948 to induce a menopause in dysfunctional bleeding, because the waiting list for hysterectomy was so long. In 1962 at the request of the late Austin Concanon, F.R.C.O.G., I attempted a survey of the results and feel that these may be of interest. From 1948-57, 678 patients were treated by deep $x$-ray therapy and a total dose of between 850 and $900 r$ was given in three consecutive daily treatments to the midpoint of the pelvis. During the first five years 18 patients out of 380 required further treatment, while in the second five-year period four patients only needed it. There was no primary mortality rate, but at the time of my survey nine patients had died; seven from unrelated causes, but it was significant that two died of ovarian carcinoma. Three cancers of the uterine corpus had been detected following irradiation up to the time of the survey, and treated by hysterectomy.

In an attempt to investigate the morbidity of the method of treatment all 292 patients treated in the second five-year period were invited by letter to attend an outpatien clinic. Unfortunately only 163 were eventually seen; Plymouth at this time had a shifting population due to Service movements and re-settlement so that it was not felt that the survey had any validity and it was not published. The results obtained are best summarized as follows:

Total number interviewed

Treatment effective

Glad they had it done

Would have preferred hysterectomy

Would recommend treatment

Complained of nausea

Complained of flushing and other menopausal symptoms

Hysterectomy performed later

Evidently the charge could be levelled that only the satisfied clients had been interviewed, but the low incidence of side effects surprised me. The majority of patients admitted to symptoms of lassitude and depression in the week following treatment, but postirradiation nausea was unusual. The impression at the end of this survey was that subject to the safeguards emphasized in your leader there was still a place for radiation menopause in the treatment of dysfunctional bleeding, particularly where a long waiting list precluded early hysterectomy as a definitive treatment.-I am, etc.,

Nassau,

ROGER DOHERTY

Bahamas

\section{Lithium-induced Diabetes Insipidus}

SIR,-At least in a detail your leading article "Lithium-induced Diabetes Insipidus" is misleading (24 June, p. 726). It misquotes Harris and Jenner ${ }^{1}$ as implying that caesium and lithium have similar inhibiting effects on the action of vasopressin. In fact, they got no clear results studying caesium. The reference to Hynie and Sharp ${ }^{2}$ which is from work on toads' bladders is also very selective, for in that system potassium, magnesium, barium, manganese, calcium, and strontium all inhibit vasopressin..$^{34}$ Further using that model lithium inhibits the effects of cyclic A.M.P. on water transport. ${ }^{5}$

It is difficult to get all these things right, and perhaps of little relevance to a general clinical audience, but nevertheless I hope you feel worth correcting.-I am, etc.,

\section{F. A. JENNER}

M.R.C. Unit for Metabolic Studies in Psychiatry, University Department of Psychiatry,

\section{Middlewood Hospital,}

Harris, Carol A., and Jenner, F. A., Fournal of Physiology, 1969, 203, 73.

ynie, S., and Sharp, G. W. G., Fournal of Endocrinology, 1971, 50, 231 .
Bentley, P. J., fournal of Endocrinolgy, 1959, 18. 327

Harris, Carol A., and Jenner, F., A., British Fournal of Pharmacology, 1972, 44, 223 .
Harris, Carol A., and Jenner, F. A., fournal de Pharmacologie, 1971, 2, 215.
Phis, Carol A., and Jenner,

\section{Payment by Colour}

SIR,-Although we have been tremendously interested in the arguments on "Payment by Colour" pursued in these columns we have refrained from contributing to them for a number of reasons, one of which is that our point of view coincides largely with that of Dr. A. B. Kazi (27 May, p. 532). However the opinions of Dr. J. K. McKechnie 29 April, p. 291) and Dr. W. P. P. Leary (17 June, p. 715) require reiteration of certain facts and clarification of the issues involved in South Africa.

The failure of the South African government to provide essentials for its Black majority and its policy of naked discrimination need no elaboration here. The point at issue is whether the B.M.F., with its nonracial principles, can be consistent in advertising hospital and university posts in South Africa. If Dr. McKechnie's and Dr. Leary's suggestions are followed, we feel that the B.M.F. would be helping to perpetuate the iniquitous sequence of events which result in poor medical services in South Africa and the neglect of Black needs.

It is our opinion that the B.M.F. would be working in our long term interests if it discontinued advertising for these posts from South Africa. In view of the outstanding service of the mission hospitals to the poor and needy in this country and their policy of non-discrimination, we feel that this restriction should be relaxed in respect of their needs.

Your two correspondents from South Africa display an inadequate understanding of the problem when they say that it is the Black who will suffer if the inflow of medical personnel into South Africa is reduced. The real problem of course is the policy of this Government, which does not provide adequate education for the Blacks, which refuses to build more hospitals for us, and which keeps us in this continuing inferiority by countless measures. Our poverty contrasts with the Whites' affluence and our lack of skills with their technological superiority.

We need to consider then whether the immigration of foreign doctors would actually benefit our cause or rather work against us. The paucity of medical services for the Blacks is due entirely to a lack of Governmental concern for our needs. We can, by discouraging the inflow of foreign doctors, bring to bear on the Government the full brunt of its actions, or rather lack of them, and thereby compel it to pursue a more humane and realistic course. Immigration lends support to the structure of apartheid.

By discouraging the inflow of medical personnel into South Africa we would be in line with popular thought in industry which favours the training of Black workers for skilled jobs rather than the filling of these posts by White immigrants. Economic pressures have compelled the Nationalist Government to accept these realities with the result that we see more opportunities being created for Blacks-for example, in the railways, where these had previously been reserved for Whites.

The former Dean of Johannesburg, $G$. F. Beytagh, who has suffered for his espousal of humanitarian causes, has this to say to the British and European worker: "if you go to South Africa to work, you are a traitor to the cause of human freedom;" he also adds that "every skilled worker who goes there (South Africa) robs one African of the chance of improvement."'

Dr. Leary's implied criticism of Dr. A. B. Kazi's establishing an urban rather than a rural practice reflects an ignorance of the laws in South Africa, which prohibits the residence of all race groups in the African rural areas. Dr. Leary's assertion that "the relative shortage of medical practitioners in the African areas is not entirely the fault 